\title{
Pediculosis in a paediatric greek population: regressions of socioeconomic factors
}

\author{
George I. Lambrou ${ }^{1 *}$, Maria Braoudaki ${ }^{1}$, Eleni Papanikolaou ${ }^{2}$ and Anna Tagka ${ }^{3}$ \\ ${ }^{1}$ First Department of Pediatrics, Choremeio Research Laboratory, University of Athens, Athens-Goudi 11527, Greece \\ ${ }^{2}$ Division of Endocrinology, Metabolism and Diabetes, University of Athens Medical School, "Eugenideion” Hospital, Athens, Greece \\ ${ }^{3}$ Department of Dermatology, University of Athens Medical School, Andreas Syggros Hospital, Athens, Greece
}

\begin{abstract}
Background: Pediculosis in humans and especially children is a very common dermatological disorder caused by the parasites Pediculus bumanus capitis, Pediculus bumanus humanus and/or Pediculus phthirus pubis.

Aim: The aim of this study was to further investigate the relations of studied socioeconomic variables towards the understanding of pediculosis dynamics in the Greek population.

Materials and methods: A total of 435 parents or parent couples were investigated with respect to their socioeconomic background and the prevalence of pediculosis in their children. Linear regression has been applied in order to identify further patterns of pediculosis dynamics.

Results: Regression analysis revealed distinct dynamics with respect to several socioeconomic factors such as education and income.

Discussion: It appeared that income and education are influential with respect to the prevalence of pediculosis, while parents' gender appears also of great importance since mothers are the determining factor in pediculosis prevalence.
\end{abstract}

\section{Introduction}

Pediculosis in humans and especially in children is a very common dermatological disorder caused by the parasite Pediculus humanus capitis [1-3]. Additional human-infesting parasites include Pediculus humanus humanus and Pediculus phthirus pubis. The lice Pediculus humanus capitis is considered the most common parasite infesting children [4]. The older evidence on lice comes from an archaeological finding, a hair in north-east Brazil dating back to 8000 B.C. In humans two species of the parasites have been mainly found, the Pediculus humanus capitis and the Pediculus humanus humanus [5]. Lice are small, wingless parasites that are unable to survive without a host [6]. A louse contagion it occurs mostly in densely inhabited areas, refugee camps or asylum, prisons and especially when the hygiene conditions are not adequate or poor. Although, lice could be considered simple organisms there is not much knowledge concerning their genome. This makes the task of understanding their biology, taxonomy and epidemiology more difficult. What it is known concerning their genome is that there are three different taxonomic genomic mitochondrial axes-classes of the head lice. The three classes (A, B and C) of head lice were described by analyzing the mitochondrial DNA (cytochrome $b$ and cytochrome oxidase subunit 1), and of them, only one (clade A) was present in body lice [7]. The strange part about genomic taxonomy is that it appears that there is no distinct genomic profile for lice species, a fact that can be attributed to the phenomenon of evolution of the parasites as well as to their possible interbreeding [7].

It is considered to be an infestation of both developed as well as developing countries, in other words lice do not make discriminations. For example, in Australia it has been reported that on average 13\% of the children are being infested by louse. In Brazil the prevalence gets as high as $43 \%$ in urban areas and $28 \%$ in the rural areas. Similarly, in China the prevalence of pediculosis has been on average $14 \%$. Finally, in England it is approximately on the 2\% level [4]. Interestingly, it has been reported that in developed countries such as Canada and the United States, Caucasians are being more frequently infested as compared to black individuals [8]. Similar reports have shown that pediculosis is more frequent in low income social groups [9]. It is known that in general girls are being infested more frequently than boys and the infestation reaches its peak between the ages of 3-11 [2,4].

Despite the prevalence of the infestation, little is known on lice both from the epidemiological point of view as well as its biology. It also appears that the phenomenon of lice infestation has local characteristics varying from country to country.

We have previously reported that two main factors appearing to influence lice infestations was gender, family status further influenced by income and nationality [10]. From our previous work it appeared that there was a significant interest towards investigating influencing variables with respect to their interrelation.

Correspondence to: George I. Lambrou, First Department of Pediatrics, Choremeio Research Laboratory, University of Athens, Athens-Goudi 11527, Greece, Tel: +00302107467427; Fax: +00302107467427; E-mail: glamprou@med.uoa.gr

Key words: pediculosis, greece, socioeconomic factors, linear regression

Received: May 18, 2016; Accepted: June 02, 2016; Published: June 06, 2016 
Thus, the aim of this study was to investigate the patterns of variable relations among the factors found to influence lice infestation in children.

\section{Materials and methods}

The detailed sampling procedure has been published previously [10]. Briefly, the study was conducted in the urban area of Athens during the period 2004-2006. The target group consisted of children from the area's kindergartens. A total of 435 parents or parent couples were investigated with respect to their socioeconomic background and the incidence of pediculosis in their children. Children were between the ages of 2-6 and upon consent of the child's guardian they were included in the study. Questionnaires were filled out by a trained health professional after a children's clinical examination. For this purpose we used the assistance of the teachers from the kindergartens and primary schools. Questionnaires were anonymous, no further personal data were collected and there is no way to trace back to the identity of examined individuals from the available data. Data collected included, gender, age, education of both parents, family yearly income, parent's nationality, the type of marriage meaning if Greeks (man and woman) were being married to other nationalities or not, if children are brought about in a single family, the presence or not of pediculosis and the presence of any additional dermatological conditions. The criterion of pediculosis or dermatological conditions was considered as affirmative if the child was infested at the time of the investigation. The procedure is presented in a previous work [10]. Possible bias in the present investigation would be the misinterpretation of the questionnaire. Yet, the questionnaire was self-explanatory and the health professional was trained to overcome any obstacles.

The study was conducted after special license from the Municipality of Athens conformed to the standards set by the Declaration of Helsinki. Reporting of the study conforms to STROBE statement along with references to STROBE and the broader EQUATOR guidelines [11].

Data analysis was performed the MATLAB simulation environment (The Mathworks, Inc. Natick MA). Regression analysis has been performed using linear models of the form $y=a x+b$ and $y=a x^{2}+b x+c$. Raw

Definitions: The couples' nationality is defined as follows: Greek couples are considered those with both spouses of Greek citizenship, Other couples are considered those with both spouses of other citizenship than Greek and Mixed couples are considered those that one of the spouses is of Greek citizenship and the other of an other citizenship. The family income has been divided into three categories: less than 10 thousand euros per annum (up to $10 \mathrm{~K}$ ), between 10 thousand euros and 30 thousand euros per annum (Between $10 \mathrm{~K}$ and $30 \mathrm{~K}$ ) and more than 30 thousand euros per annum (more than $30 \mathrm{~K}$ ). Education was divided in two categories; less than 12 years and more than 12 years of total education for both genders (fathers and mothers). Raw data have been previously published by Tagka et al. (2016) [10].

\section{Results}

Regression of family income per annum manifests the larger percentage in families with income between $10 \mathrm{~K}$ and $30 \mathrm{~K}$ euros per annum, which is considered logical indicating that most families lie within the medium income (Figure 1A). Investigating the rate of pediculosis with respect to income in the total population we found that there is a decrease in pediculosis with an increasing income. This finding is interesting since it correlates pediculosis to income (Figure 1B). Getting more in depth examining the subpopulation of Greek mothers and couples we have found that income was playing a very significant role since the rate of pediculosis is reversely proportional to the family income (Figure 1C, 1D). Similarly, when examining the percentage of couples' nationality we see that Greek couples are the majority, with other nationalities following and mixed couples being at the lowest (Figure 1E). When isolating the family income with respect to nationality, we have an interesting observation. With respect to family income, couples with other nationality manifest the higher percentage in low incomes (up to $10 \mathrm{~K}$ euros) $\left(R^{2}=1\right)$. At the same time the highest incomes manifested a reversely symmetrical curve to the lowest incomes with Greek couples manifesting the highest percentages $\left(R^{2}=0.9962\right)$ (Figure $1 \mathrm{~F}$ ). Medium incomes appear to be of linear nature and consist of a bisetrix of the two previous curves $\left(R^{2}=0.9979\right)$ (Figure $1 \mathrm{~F}$ ). Examining the rate of pediculosis with respect to couples' nationality we have found that Greek and mixed couples manifested the higher pediculosis rates in their children while couples with other nationalities manifested the lower pediculosis rates in their children (Figure 1G). At the same time when examining couples' nationality in families with income between $10 \mathrm{~K}$ and $30 \mathrm{~K}$ euros per annum and children with no pediculosis, Greek couples manifested the higher pediculosis-free rates, followed by couples with other nationalities and mixed couples manifesting the lower rates $\left(R^{2}=0.991\right)$ (Figure $\left.1 \mathrm{H}\right)$. Similarly, when examining the same sub-group but having children with pediculosis, linear regression obtains an $R^{2}=0.75$, indicating a different pattern of change to a non-linear one (Figure 1I). This indicated that pediculosis in this income sub-group occurs at similar rates in Greek and other nationality couples and significantly lower in mixed couples. Linear relation was also manifested in fathers' education, with fathers having an education more than 12 years subgroup, with respect to couples' nationality where we have found that Greek couples manifest the higher pediculosis rated followed by other nationalities and mixed couples (Figure 1J). Similar pattern in pediculosis rates was found in the single parent families' subgroup with female children (Figure 1K). Plotting the percentage of each income category in Greek couples versus the percentage of income categories in couples with other nationalities we have found that children with pediculosis and with no pediculosis manifested symmetrical curves. Plotting the income percentages in Greek couples and couples with other nationalities subgroups we have found that our previous observations were confirmed. In families with children with pediculosis the percentage of Greek couples was higher than that of couples with other nationalities in the income range up to $10 \mathrm{~K}$ euros per annum (Figure 1L). This also applied to families with higher income (more than $30 \mathrm{~K}$ euros per annum). A reversal of this pattern was seen in medium incomes, where couples with other nationality and children with pediculosis had a higher rate than Greek couples. A symmetrical view was taken for families in the income categories but with pediculosis-free children (Figure 1L). When accounting for the factor of education, we have observed an interesting phenomenon. When plotting the family income in the subpopulation of mothers with education between 7 and 12 years versus the income in the father subpopulation with education more than 12 years (irrespectively of nationality) and both with children with pediculosis we get a linear pattern $\left(R^{2}=0.9973\right)$. The highest percentages of mothers and fathers having children with pediculosis were observed in the medium incomes. The lowest percentages were observed in the highest incomes, indicating that none of the fathers with education more than 12 years had children with pediculosis while $\sim 15 \%$ if the mothers with education between 7 and 12 years had (Figure $1 \mathrm{M}$ ). When 

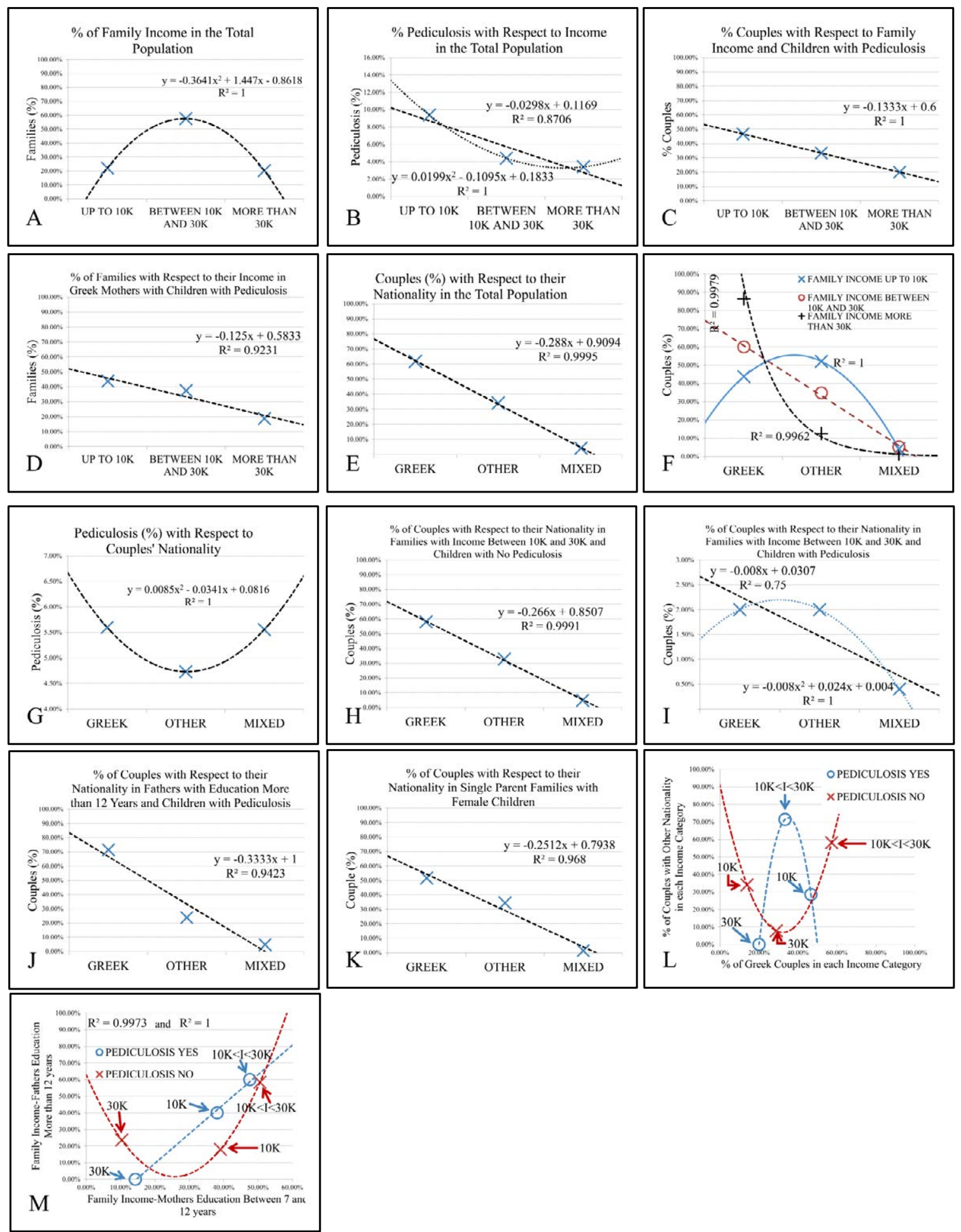

Figure 1. Regression of variables.

Regression of family income per annum in the total population (A), pediculosis with respect to income (B), family income in families with children with pediculosis $(\mathbf{C})$, population of Greek mothers with children with pediculosis $(\mathbf{D})$, couples with respect to their nationality in the total population (E), regression of percentages of couples' nationality with respect to family income percentages in the total population $(\mathbf{F})$, pediculosis with respect to couple nationality $(\mathbf{G})$, regression of percentages of couples nationality within the population of families with income between $10 \mathrm{~K}$ and $30 \mathrm{~K}$ and children with no pediculosis $(\mathbf{H})$, regression of percentages of couples nationality within the population of families with income between $10 \mathrm{~K}$ and $30 \mathrm{~K}$ and children with pediculosis $(\mathbf{I})$, regression of percentages of couples nationality within the population of fathers with education more than 12 years and children with pediculosis $(\mathbf{J})$, percentage of couples with respect to their nationality in single parent families with female children (K), regression of percentages of Greek couples family income with respect to to the family income of couples with other nationality $(\boldsymbol{I}$ : Income) $(\mathbf{L})$, regression of percentages of family income within the population of mothers with education between 7 and 12 years with respect to the family income within the population of fathers with education more than 12 years (I: Income) (M) (The couples' nationality is defined as follows: Greek couples are considered those with both spouses of Greek citizenship, Other couples are considered those with both spouses of other citizenship than Greek and Mixed couples are considered those that one of the spouses is of Greek citizenship and the other of an other citizenship). 
examining the same subgroups but with pediculosis-free children the pattern becomes non-linear (polynomial $R^{2}=1$ ) with the income groups following the same sequence as in the pediculosis-positive subgroup (Figure 1M).

Based on our study, total infestation rate was found to be at the $\sim 5 \%$ level (5.3\%), while reports on pediculosis prevalence vary between countries and populations studied. It appears that pediculosis really varies based on the method of study and the geographic location. In four studies in Greece we have seen that the prevalence of pediculosis rose significantly during the recent years (Figure 2A). Interestingly, in the other studies in Greece as compared to our study the rate of other nationalities participating in the studies decreased (Figure 2B) as also did the higher incomes prevalent with pediculosis (Figure 2C). The lowest rates of pediculosis were observed in Germany and Poland (Figure 2D, 2E). From available data pediculosis in the UK appeared to manifest a reverse bell-shape, with an increasing tendency up to 1997 (Figure 2F).

\section{Discussion}

Pediculosis capitis, tends to be an increasing problem within the children population. The interesting concept of pediculosis is that there is little known about lice biology. Understanding the mechanisms through which humans get infested by these parasites is of great importance, especially in times where socioeconomic factors are at decay. The problem with these parasites is not the sole infestation but the ability to transmit other bacterial or viral generated diseases, as it has been recently proposed for the Dark Ages [12]. Another important finding is that lice can and probably have become resistant to current treatments, which indicates a remarkable mechanism of survival and thus of need of research on the field of prevention and treatment, which applies both to animal and human infesting parasites [13,14].

In the present work we have investigated the patterns of socioeconomic (such as origin of the parents, income and education) factors influencing the prevalence of pediculosis in the kindergartens of Athens as well as we have performed several regression analysis attempts in order to unravel its dynamics. There are not many works in the literature handling this topic especially for the Greek area. To the best of our knowledge this is the first study that provides a regression analysis for these variables together and in that extent.

Infestations were found to be at the $\sim 5 \%$ level (5.3\%), while reports on pediculosis prevalence vary between countries and populations studied. It appears that pediculosis really varies based on the method of study and the geographic location. In four studies in Greece we have seen that the prevalence of pediculosis rose significantly during the recent years $[15,16]$. Interestingly, in the other studies in Greece as compared to our study the rate of other nationalities participating in the studies decreased as also did the higher incomes prevalent with pediculosis. The lowest rates of pediculosis were observed in Germany and Poland [17,18]. Another interesting observation, holding as correct the study of Doulgeraki et al. (2011), was that the high rates of pediculosis coincided with the recession years in Greece. It has been reported that pediculosis rates increase in areas or in times of population impoverishment [19-23].

Pediculosis in the general population follows polynomial dynamics, while in the percentages of couples, which have children with pediculosis the dynamics become linear $\left(R^{2}=1\right)$. This is a strong indicator, also mentioned before in the literature, that impoverishment enhances lice infestation. This can be explained by the fact that pour
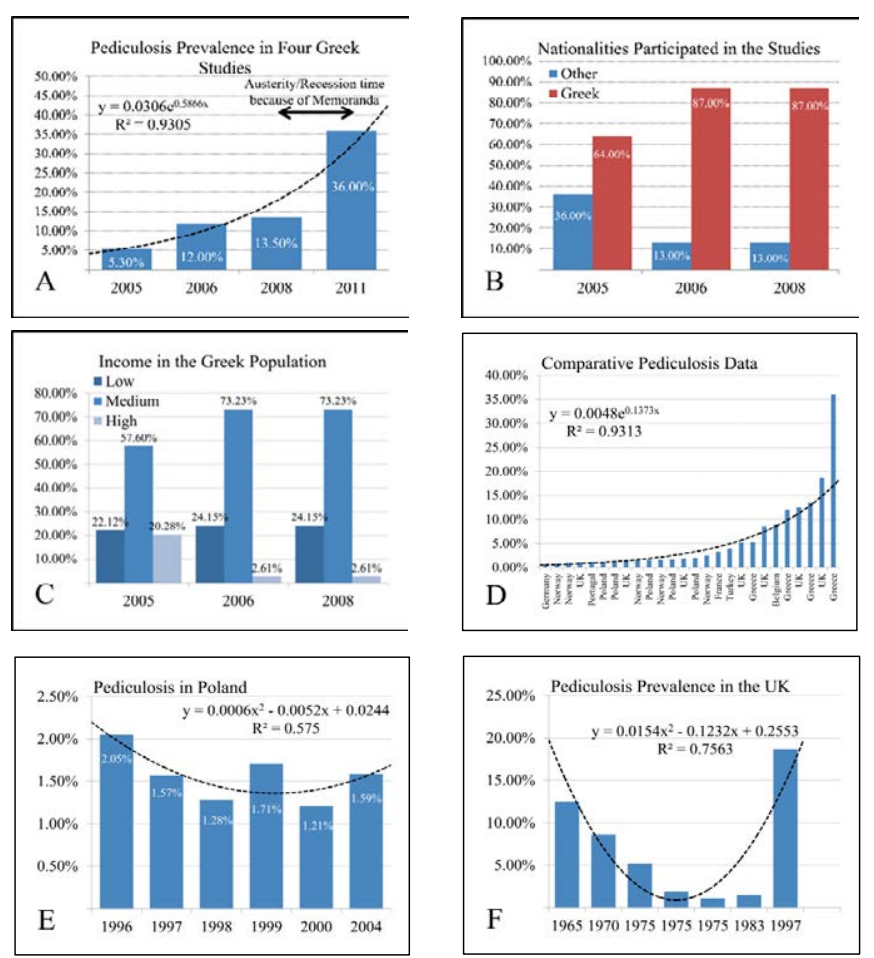

Figure 2. Comparative data from Greek and other studies with respect to pediculosis.

Pediculosis percentages in four studies in respectively as much Greek studies (A). Comparison of three studies in Greece with respect to nationality of participants (B). Comparison of three studies in Greece with respect to income of participants (C) Comparison of pediculosis between countries in equal studies from respective countries (D). Time series of pediculosis in Poland (E). Time series of pediculosis in the UK (F).

families do not have access either to prevention methods, clothes, hygiene conditions or even social infrastructures. Similarly, linear dynamics were followed when examining the percentages of families, whose mother is of Greek origin and with respect to income, as well as in single parent families. Plotting Greek couples versus other nationality couples with respect to income and pediculosis it has confirmed our previous observations, where in low incomes more Greek families have children with pediculosis as compared to other families and in medium incomes this is reversed. The peak of the curve for pediculosis-positive children is at the medium income, while for pediculosis-free children is at the high incomes. The curves appear to be symmetrical which stresses the significance of income in the rates of pediculosis.

Another interesting observation, that was abstracted from our results, was the fact that when examining the role of education and income, it appeared that in pediculosis positive cases, in higher incomes mothers' education plays more critical role than fathers' education. This is balanced out in lower incomes, where the percentages of fathers and mothers are similar. This pattern changes in pediculosis negative cases, where higher incomes are balanced, with fathers and mothers participating equally to pediculosis incident, but at lower incomes mothers are again the more influential, indicating that probably they are the ones "saving" their children from phthiriasis. This is an interesting result since it shows that income influences mothers, which influence pediculosis prevalence further on.

As it has been stressed in other reports too, pediculosis is a common infestation, yet we do not have a plethora of data in order to understand its dynamics and epidemiology. Furthermore, it appears that genomic 
studies are also scarce. It has been probably neglected as a topic since it appears that its presence and treatment are taken for granted. Yet, the increasing observations on therapy-induced resistance and the fact that lice can be the vector for other diseases makes it necessary that further studies should be conducted on this topic, especially in this era where geopolitical events force human beings to relocate.

Concluding, in the present study we have investigated the interrelation of several infestation-influencing factors in the studied population, we have identified subpopulation characteristics that influence lice infestation and finally it appeared from our findings that lice infestation is not anthropocentric but it is environmental/ circumstantial-specific.

\section{Aknowledgements}

This work was funded in part by the University of Athens, Medical School.

\section{Disclosures and conflict of interest}

The authors have nothing to disclose and no conflict of interest.

\section{References}

1. Devore CD, Schutze GE; Council on School Health and Committee on Infectious Diseases, American Academy of Pediatrics (2015) Head lice. Pediatrics 135: e13551365. [Crossref]

2. Harris J, Crawshaw JG, Millership S (2003) Incidence and prevalence of head lice in a district health authority area. Commun Dis Public Health 6: 246-249. [Crossref]

3. Feldmeier H (2014) Treatment of pediculosis capitis: a critical appraisal of the current literature. Am J Clin Dermatol 15: 401-412. [Crossref]

4. Feldmeier H (2012) Pediculosis capitis: new insights into epidemiology, diagnosis and treatment. Eur J Clin Microbiol Infect Dis 31: 2105-2110. [Crossref]

5. Irvine AD, PH Hoeger, and AC Yan (2011) Harper's Textbook of Pediatric Dermatology. Wiley.

6. Burns T, et al, Rook's Textbook of Dermatology, 4 Volume Set. 2010: Wiley.

7. Boutellis A, Abi-Rached L, Raoult D3 (2014) The origin and distribution of human lice in the world. Infect Genet Evol 23: 209-217. [Crossref]

8. Bonilla DL (2013) The biology and taxonomy of head and body lice--implications for louse-borne disease prevention. PLoS Pathog 9: e1003724.
9. AlBashtawy M, Hasna F (2012) Pediculosis capitis among primary-school children in Mafraq Governorate, Jordan. East Mediterr Health J 18: 43-48. [Crossref]

10. Tagka A, Lambrou GI, Braoudaki M, Panagiotopoulos T, Papanikolaou E, et al. (2016) Socioeconomical Factors Associated With Pediculosis (Phthiraptera: Pediculidae) in Athens, Greece. J Med Entomol. [Crossref]

11. Simera I, Moher D, Hoey J, Schulz KF, Altman DG, et al. (2010) A catalogue of reporting guidelines for health research. Eur J Clin Invest 40: 35-53. [Crossref]

12. Ayyadurai S, Sebbane F, Raoult D, Drancourt M (2010) Body lice, yersinia pestis orientalis, and black death. Emerg Infect Dis 16: 892-893. [Crossref]

13. Heath A, Levot GW (2015) Parasiticide resistance in flies, lice and ticks in New Zealand and Australia: mechanisms, prevalence and prevention. N Z Vet J 63: 199-210. [Crossref]

14. Kwon DH, Kim JH, Kim YH, Yoon KS, Clark JM, et al. (2014) Identification and characterization of an esterase involved in malathion resistance in the head louse Pediculus humanus capitis. Pestic Biochem Physiol 112: 13-18. [Crossref]

15. Soultana V, Euthumia P, Antonios M, Angeliki RS (2009) Prevalence of pediculosis capitis among schoolchildren in Greece and risk factors: a questionnaire survey. Pediatr Dermatol 26: 701-705. [Crossref]

16. Vladeni S, Petinaki E, Roussaki-Schultze A (2011) Hair characteristics and lice infestation. Data from schoolchildren in Greece. $J$ Eur Acad Dermatol Venereol 25 : 118-119. [Crossref]

17. Buczek A, Markowska-Gosik D, Widomska D, Kawa IM (2004) Pediculosis capitis among schoolchildren in urban and rural areas of eastern Poland. Eur J Epidemiol 19 491-495. [Crossref]

18. Rukke BA (2011) Head lice prevalence among households in Norway: importance of spatial variables and individual and household characteristics. Parasitology 138: 1296-304.

19. El-Bahnasawy MM, FE Abdel, TA Morsy (2012) Human pediculosis: a critical health problem and what about nursing policy? J Egypt Soc Parasitol 42: 541-62.

20. Heukelbach J, Wilcke T, Winter B, Feldmeier H (2005) Epidemiology and morbidity of scabies and pediculosis capitis in resource-poor communities in Brazil. Br J Dermatol 153: 150-156. [Crossref]

21. Lesshafft H, Baier A, Guerra H, Terashima A, Feldmeier H (2013) Prevalence and risk factors associated with pediculosis capitis in an impoverished urban community in lima, peru. J Glob Infect Dis 5: 138-143. [Crossref]

22. Maxwell M, B Crawford, V Rose (2014) Nitbusters: lessons from a school-based intervention study to reduce head lice in a disadvantaged community. Health Promot $J$ Austr 25: 67-68

23. Ortega-Marin L (2013) Effect of households' social networks on lice infestation among vulnerable Mexican children: a qualitative comparative analysis. J Trop Pediatr 59: 413-418

Copyright: (C2016 Lambrou GI. This is an open-access article distributed under the terms of the Creative Commons Attribution License, which permits unrestricted use, distribution, and reproduction in any medium, provided the original author and source are credited. 